\title{
EDITORIAL
}

\section{REAFIRMAR A DEFESA DO SISTEMA DE CIÊNCIA, TECNOLOGIA E ENSINO SUPERIOR PÚBLICO BRASILEIRO}

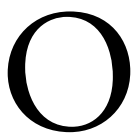

ano de 2019 veio confirmar e radicalizar tendências já delineadas no Brasil, resultantes do processo de ruptura democrática e crescente autoritarismo que marca o nosso tempo. Nos campos da educação, da ciência e da tecnologia, veem-se o esvaziamento orçamentário e os riscos de desmonte de todos os sistemas de políticas de Estado paulatinamente construídos ao longo de décadas de trabalho e investimentos públicos. Tudo isso na contramão da legislação e do planejamento público aprovado até 2016, especialmente o Plano Nacional de Educaçáo 2014-2024 (PNE, Lei no 13.005/2014).

A autonomia das universidades federais e a ciência vêm sendo acintosamente atacadas, em diversas frentes. Em abril, o anúncio de um corte brutal no orçamento das universidades e institutos federais colocou em risco o funcionamento das instituiçóes e impulsionou a Greve Nacional da Educação, em 15 de maio, com grande adesáo em todo o país. Tais mobilizaçóes obrigaram o governo Bolsonaro a recuar parcialmente nos cortes, recompondo uma parcela dos orçamentos das instituiçóes e mudando o discurso: trata-se, agora, de um contingenciamento temporário. É fato, entretanto, que o funcionamento das instituiçōes segue ameaçado, já que de 15 a 20\% dos recursos previstos na Lei Orçamentária de 2019 continuavam contingenciados até meados de outubro (ANDIFES, 2019a).

Essa ameaça, contudo, não se restringe a 2019, mas tende a permanecer nos próximos anos. A Emenda Constitucional $\mathrm{n}^{\circ}{ }^{\circ} 95 / 2016$ determina uma espécie peculiar de estado de sítio fiscal (PINTO; BIASOTO JUNIOR, 2016), ao estabelecer como limite para as despesas primárias da União Federal, até 2036, as despesas executadas em 2016 atualizadas pela inflação., Assim, modifica-se,inconstitucionalmente, o critério de cálculo dos mínimos obrigatórios a serem aplicados em saúde e educaçáo, ou seja, uma

versão para o orçamento do Estado social e os DESC [Direitos Econômicos, Sociais e Culturais] do estado de sítio propriamente dito e sua prerrogativa de suspender as garantias constitucionais (CF88, arts. 137 e 138), no caso as garantias de piso de financiamento público a tais direitos no âmbito da União, inscritos na CF88 (PINTO; XIMENES, 2018, p. 995).

Em função dessa medida e da opçáo de Bolsonaro por reduzir as despesas com educação pública, o Projeto de Lei Orçamentária Anual de 2020 (PLOA, 2020),

DOI: $10.1590 / E S 0101-73302019230375$

Educ. Soc., Campinas, v.40, e0230375, 2019 
encaminhado em agosto ao Congresso, estabelece redução da ordem de $18 \%$ nos recursos totais do Ministério da Educaçáo (MEC). Com isso, cortam-se os investimentos na ampliaçấo do acesso, inclusive aquele necessário à conclusăo das obras já iniciadas.

Mais grave é o cenário de investimentos em pesquisa: já profundamente afetados em 2019 pelos cortes, que levaram à suspensão de editais em andamento e ao corte de bolsas em implementação, a Coordenação de Aperfeiçoamento de Pessoal de Nível Superior (CAPES) e o Conselho Nacional de Desenvolvimento Científico e Tecnológico (CNPq) têm seus orçamentos reduzidos à metade no PLOA 2020 (BRASIL, 2019a).

Esse cenário, lamentavelmente, guarda coerência com a repetida e manifesta intenção de Bolsonaro e seu ministro Weintraub de reduzir a autonomia didático-científica, administrativa e de gestão financeira e patrimonial das universidades, na medida em que se colocam, mais uma vez, contra a Constituição e a favor da censura. A demissão de Ricardo Galvão do comando do Instituto Nacional de Pesquisas Espaciais (Inpe), em represália à divulgação dos dados alarmantes sobre o desmatamento na Amazônia Legal, uma atribuição ordinária da instituição, é um marco nesse processo, mas não o único. A prática de nomear reitores não escolhidos pelas comunidades universitárias se dissemina. Chegou-se ao cúmulo de indicar à reitoria um candidato que obteve somente $4,6 \%$ dos votos na consulta pública a estudantes, técnicos e professores.

Não há dúvidas, portanto, sobre a intenção do governo federal de atacar ou mesmo desmontar o sistema de ciência, tecnologia e ensino superior público brasileiro. A intenção oficial de privatização não é mera especulação, mas está expressa na proposta do MEC de reforma desse setor, o Programa Institutos e Universidades Empreendedoras e Inovadoras - FUTURE-SE, uma minuta de Projeto de Lei posta em discussão em julho.

Partindo de um equivocado diagnóstico sobre os problemas do ensino e da pesquisa no Brasil, sem qualquer referência à ideia de direito à educação e às metas do PNE, o MEC propóe um amplo leque de instrumentos de privatização das instituiçóes federais de ensino, com medidas que iriam da transferência parcial da gestáo dos recursos públicos para Organizaçóes Sociais (OS) à exploração de naming rights e mesmo à dilapidação do patrimônio público, com doações não onerosas e a cessão de uso de imóveis à iniciativa privada (BRASIL, 2019b). Como pano de fundo, mais uma vez, está o ataque à autonomia e a manifesta intençáo de quebrar o seu elemento institucional mais relevante, ou seja, a carreira docente estável e o concurso público a ela associado, permitindo-se a contratação precária de docentes via OS.

O ano de 2019, nesse contexto, é de embates decisivos em defesa da educação pública e da ciência. Constroem-se novos modos de resistência. Até setembro, a maioria das universidades já havia rejeitado o Future-se, por considerá-lo contrário aos preceitos constitucionais de autonomia. A Associação Nacional dos Dirigentes das Instituiçóes Federais de Ensino Superior (Andifes), na Carta de Vitória (ANDIFES, 2019b), dá a exata noção do que está em jogo no atual contexto: 
O sistema de universidades federais é um patrimônio de nosso povo. Elas representam uma das apostas mais significativas da sociedade brasileira no conhecimento, na ciência, na formação de recursos humanos, no desenvolvimento social e tecnológico, na cultura e nas artes. A educação pública é, desse modo, uma recusa sistemática do atraso e da ignorância, uma opção atual e de longo prazo pela civilização (ANDIFES, 2019b).

Em seus mais de 40 anos de existência, a revista Educação \& Sociedade acompanhou embates decisivos no campo das políticas educacionais. Constituiu-se, desde sua criação, em arena de disseminação de conhecimento, divulgação científica e debates fundamentais, sempre com grande aceitação na comunidade acadêmica. A defesa da educação pública, gratuita, laica, com qualidade e socialmente referenciada, conforme inscrita na Constituição Federal de 1988, é princípio de nossa publicação. Nesse âmbito, está a educação democrática e, como decorrência, estão também as liberdades educacionais de ensinar, aprender, pesquisar e divulgar a arte e o saber, o pluralismo de ideias e de concepçóes.

Também enfrentamos severos desafios no atual momento e passamos por importantes mudanças no processo editorial, sempre com o propósito de excelência que nos caracteriza. Contemplando as boas práticas de edição de periódicos científicos, Educação \& Sociedade E\&S adotou a publicação contínua, operando exclusivamente com volume, calendário e publicação on-line na Coleção Biblioteca Eletrônica Científica Online (SciELO). As impressões e os fascículos não são mais correntes na revista.

Quando a educação pública no Brasil enfrenta os maiores ataques jamais vivenciados, por parte do governo central, Educação \& Sociedade reafirma seus princípios políticos e editoriais e convida leitores, autores e corpo editorial a seguirem resistindo ativamente em defesa do patrimônio educacional duramente conquistado.

\section{Referências}

ASSOCIAÇÃO NACIONAL DOS DIRIGENTES DAS INSTITUIÇŌES FEDERAIS DE ENSINO SUPERIOR (ANDIFES). Andifes comenta descontingenciamento parcial de recursos para as universidades federais feito pelo MEC. ANDIFES, 30 set. 2019a. Disponível em: $<$ http://www.andifes.org.br/andifes-comenta-descontingenciamento-parcialde-recursos-para-as-universidades-federais-feito-pelo-mecl>. Acesso em: $1^{\circ}$ out. 2019.

ASSOCIAÇÃO NACIONAL DOS DIRIGENTES DAS INSTITUIÇÓES FEDERAIS DE ENSINO SUPERIOR (ANDIFES). Carta de Vitória. ANDIFES, jul. $2019 \mathrm{~b}$. Disponível em: <http://www.andifes.org.br/andifes-carta-de-vitoria/>. Acesso em: $1^{\circ}$ out. 2019. 
BRASIL. LOA 2020: Projeto de Lei no 22/2019-CN. Estima a receita e fixa a despesa da União para o exercício financeiro de 2020. 2019a. Disponível em <https://www2.camara. leg.br/orcamento-da-uniao/leis-orcamentarias/loa/copy of 2019/tramitacao/propostado-poder-executivo $>$. Acesso em: $1^{\circ}$ out. 2019.

BRASIL. Ministério da Educação. Institui o Programa Institutos e Universidades Empreendedoras e Inovadoras - FUTURE-SE, e dá outras providências. 2019b. Disponível em: <http://www.ufabc.edu.br/images/conteudo/pl future-se.pdf $>$. Acesso em: $1^{\circ}$ out. 2019.

PINTO, E. G.; BIASOTO JUNIOR, G. Suspender ou adiar custeio de direitos fundamentais nem deveria ser cogitado. Consultor Jurídico, São Paulo, 3 jul. 2016. Disponível em: <https://www.conjur.com.br/2016-jul-03/adiar-custeio-direitos-fundamentaisnemdeveria-cogitado $>$. Acesso em: 7 jun. 2018.

PINTO, E. G.; XIMENES, S. B. Financiamento dos Direitos Sociais na Constituição de 1988: do "pacto assimétrico" ao "estado de sítio fiscal”. Educação e Sociedade, Campinas, v. 39, n. 145, p. 980-1003, dez. 2018. Disponível em: <http://www.scielo.br/scielo. php?script $=$ sci arttext $\&$ pid $=S 0101-73302018000400980 \& \operatorname{lng}=\mathrm{pt} \& \mathrm{nrm}=\mathrm{iso}>. \quad$ Acesso em: $1^{\circ}$ out. 2019. http://dx.doi.org/10.1590/es0101-73302018209544

\author{
Salomáo Barros Ximenes ${ }^{1}$ (D) \\ Ivany Rodrigues Pino ${ }^{2}$ (D) \\ Theresa Adriáoº \\ Luana Costa Almeida ${ }^{3}$ (D) \\ Antonio Álvaro Soares Zuin ${ }^{3}$ (D) \\ Carmen Sylvia Vidigal Moraes ${ }^{4}$ (D) \\ Celso Joáo Ferretti 5 (D) \\ Pedro Goergen 6 ,7 (D) \\ Sandra Maria Zákia Lian Souza ${ }^{4}$ (D)
}

\footnotetext{
${ }^{1}$ Editor Associado. Universidade Federal do ABC - São Bernardo do Campo (SP).

${ }^{2}$ Editora. Universidade Estadual de Campinas - Campinas (SP), Brasil.

${ }^{3}$ Editor(a) Associado(a). Universidade Federal de São Carlos - São Carlos (SP), Brasil.

${ }^{4}$ Editora Associada. Universidade de São Paulo - São Paulo (SP), Brasil.

${ }^{5}$ Editor Associado. Centro de Estudos Educação e Sociedade, Universidade Estadual de Campinas -

Campinas (SP), Brasil.

${ }^{6}$ Editor Associado. Universidade de Sorocaba - Sorocaba (SP), Brasil.

${ }^{7}$ Universidade Estadual de Campinas - Campinas (SP), Brasil.
} 